Artigo

\title{
Entre a cosmopolítica e a cosmohistória: tempos fabricados e deuses xamãs entre os astecas ${ }^{1}$
}

Entre cosmopolítica y cosmohistória: tiempos fabricados y dioses chamanes entre los aztecas

Federico Navarrete Linares

Universidad Nacional Autónoma de México, Cidade do México, DF, México

fnl@unam.mx

RESUMO: Este artigo propõe uma nova interpretação da mitologia e a religião asteca ou mexica, conjuntamente com sua política. Embora tenham sido uma sociedade hierárquica com poder centralizado, os Mexica praticavam uma cosmopolítica análoga às praticas dos povos amazônicos. Neste sentido, relatos da criação do mundo mostram a maneira como seres (humanos e não humanos) com poderes xamânicos se transformam em deuses, os quais criaram os humanos numa relação de constante metamorfose e intercâmbio. Analisa-se aqui também como a prática cosmopolítica mexica tentava manter o funcionamento de uma sociedade estratificada ao mesmo tempo em que o funcionamento de um cosmos hierarquizado entre deuses e humanos. O objetivo era construir verticalidades num pluriverso que tendia sempre a voltar às transformações horizontais e gerar as relações entre os seres e realidades diferentes por meio da cosmohistória.

PALAVRAS-CHAVE: cosmogonia, xamanismo, cosmopolítica, hierarquia. 


\section{O retorno a Aztlan}

A história aconteceu supostamente no que chamamos de século xv, quando os Asteca ou Mexica estavam no ápice de seu poder imperial, e foi recolhida pelo cronista espanhol Diego Durán um século depois (1995: 268-278). Conta-se que, em meio a suas glórias, o tlatoani ou governante mexica Moteuhczoma Ilhuicamina lembrou-se que seu deus patrono, o belicoso Huitzilopochtli, tinha uma dívida com a mãe, Coatlicue, nome que quer dizer "a de saia de serpentes". Sem demora, Moteuhczoma ordenou que fosse enviada uma embaixada de guerreiros e dignitários à casa da deusa, na longínqua Aztlan, para levar-lhe presentes suntuosos em nome de seu filho, o deus que a havia deixado para acompanhar seu povo mexica em suas viagens e vitórias militares. Entretanto, ele foi logo informado que os guerreiros mexicas não podiam chegar a Aztlan, pois o caminho ao lugar de origem de seu deus e de seu povo estava "vedado" por um deserto implacável.

Ele mandou então chamar os mais poderosos nahuales de seu império, magos prodigiosos que podiam se transformar em animais e transpor os limites do mundo conhecido. Esses "bruxos" realizaram os rituais necessários e se transportaram na forma de animais selvagens até a inacessível Aztlan. Quando os embaixadores mexicas comunicaram sua missão e explicaram que eram os descendentes distantes das pessoas que haviam partido de Aztlan junto com Huitzilopochtli, os habitantes do lugar perguntaram surpreendidos: "Mas o que os matou?". Depois explicaram que ali continuavam vivos todos aqueles que haviam visto os emigrantes partir. Ali ninguém morria porque os velhos somente tinham que subir as ladeiras do Monte Curvado, o Colhuacan, onde vivia Coatlicue, para rejuvenescer até ter a idade que desejassem voltar a ter.

Porém, quando os nahuales mexicas tentaram seguir aos moradores de Aztlan pela ladeira da colina, afundaram-se tanto na areia que não puderam mais caminhar. Então, os outros lhes explicaram que não podiam escalar porque comiam alimentos demasiadamente luxuosos, particularmente o chocolate vindo de terras distantes, e não a dieta simples que eles ingeriam.

A mãe de Huitzilopochtli desceu para encontrá-los e surpreendeu-lhes com sua feiúra e imundice. Ela explicou, sem parar de chorar, que havia vivido em luto desde a partida de seu filho e que não fazia mais nada além de esperar seu regresso. Quando viu os valiosos presentes que foram enviados a ela pelo governante mexica em nome de Huitzilopochtli, repudiou-os irada e demonstrou completa indiferença diante do relato que fizeram sobre 
as glórias, conquistas e riquezas dos Mexica. Em troca, somente os lembrou que seu filho havia prometido voltar a Aztlan o mais rápido possível, pois já sabia, antes mesmo de partir, que assim como os Mexica iriam conquistar o mundo inteiro, logo o tornariam a perder, da mesma maneira que o ganharam. Para lembrar seu filho de sua promessa descumprida, enviou-lhe como presente um par de humildes sandálias e uma manta de fibra áspera, para que voltasse com elas vestidas a seu lado.

Muitos nahuales morreram no caminho de volta a México-Tenochtitlan. Os sobreviventes transmitiram a triste mensagem a Moteuhczoma Ilhuicamina, o qual ficou cheio de temor pelo destino dramático que esperava seu povo.

\section{Um trânsito xamânico²}

Tradicionalmente este relato tem sido interpretado como uma "fábula" ou "lenda" carente de qualquer realidade. Diversos autores propõem que ela foi inventada muito tempo depois dos acontecimentos do século XV os quais pretendia descrever, após a conquista espanhola de 1521, como uma explicação e justificativa dela (López Austin, 2009: 185). Segundo esta visão historicista, tratar-se-ia de uma falsa profecia da chegada dos espanhóis e da queda dos Mexica, um consolo inventado por um povo derrotado.

Uma maneira diferente de analisar este relato deve começar por compreender as transformações "sobrenaturais" que permitiram aos enviados do governante mexica chegar a Aztlan. Os nahuales, como já mencionei, são pessoas com a capacidade excepcional de se transformar em outros seres, animais, deuses ou "fenômenos naturais", como o raio. Essa capacidade de transformação lhes permite, por sua vez, aventurar-se em lugares externos ao mundo "normal" dos seres humanos, através dos níveis cósmicos e negociar com seres que neles habitam; permite-lhes também viajar por distâncias temporais, em direção ao que nós consideramos como passado e futuro (Martínez, 2011; Navarrete Linares, 2000).

Somente por meio desta mudança de corporalidade os embaixadores foram capazes de sair do âmbito espaço-temporal da ação humana habitual, o tlaltícpac, a superfície da terra e penetrar o âmbito espaço-temporal de Aztlan, distinto e incomensurável em relação ao seu. Em outros termos, realizaram uma viagem xamânica para estabelecer relações cosmopolíticas com os habitantes deste outro âmbito. Neste novo relacionamento, os enviados e seus anfitriões descobriram uma diferença corporal essencial: enquanto os habitantes do tlaltícpac 
tinham corpos pesados que os condenavam a morrer, os de Aztlan tinham corpos mais leves e portanto, podiam ultrapassar a mortalidade. Esse contraste material é atribuído de maneira direta às suas dietas: uma alimentação luxuosa que incluía chocolate para os Mexica; uma dieta mais simples para os de Aztlan. De maneira mais ampla, a alimentação se vinculava com os modos de vida como um todo: a opulência e poder dos Mexica contra a simplicidade e pobreza dos habitantes de Aztlan.

\section{Os dois cronotopos}

No entanto, as diferenças que encontraram iam além da corporalidade e da dieta, ou do que nós chamaríamos cultura e ordem social. Em Aztlan e em México-Tenochtitlan existiam dois cronotopos distintos, ou seja, duas configurações diferentes do espaço-tempo e do fluxo temporal. Associavam-se a eles duas definições ontológicas distintas da existência humana e divina. Foram essas diferenças que provocaram o fracasso da complexa negociação cosmopolítica entabulada por Moteuhczoma Ilhuicamina e seus embaixadores.

Retomo aqui as ideias de Johannes Neurath (2016) sobre os Wixarika, ou Huichol do México ocidental, para propor que os Mexica pertenciam a um cronotopo solar "artificial", enquanto Aztlan e seus habitantes estavam imersos em um cronotopo terrestre imanente ou “natural". Vejamos as principais características de cada um, começando pelo terrestre.

O cronotopo terrestre da montanha, ao qual pertencia Aztlan, havia existido desde sempre e provavelmente deveria seguir existindo eternamente, pois era uma realidade imutável associada ao inframundo e aos céus que rodeavam o tlaltícpac. Trata-se de um espaço-tempo no qual nada acontece. Coatlicue, sua dona, vive em um estado de espera permanente, chorando sem cessar pela partida de seu filho; em outros relatos, não faz nada mais que varrer e varrer numa penitência sem fim. O relato evita de maneira sistemática qualificá-la como uma deusa e aos outros habitantes de Aztlan como seres humanos ou deidades porque nesse cronotopo não existe uma distinção ontológica entre uns e outros, assim como não há diferença entre vida e morte. Os seres que o habitam vivem em um estado de indefinição cronológica, à espera de uma irrupção proveniente de outros cronotopos.

Em contraste, o cronotopo solar ao qual pertenciam os Mexica, não era eterno, mas tinha uma data de origem muito clara e uma data final igualmente definida. Todos sabiam que seria destruído em um dia do signo calendário 4-movimento, por meio de terríveis 
terremotos, como os sóis anteriores foram destruídos por outros cataclismos. Ao mesmo tempo, pereceriam também os seres humanos que foram criados com ele, como haviam sido exterminadas as humanidades anteriores. Tão importante era esse final, que o dia de sua destruição dava nome ao sol que o iluminava e a seu cronotopo (Moreno de los Arcos, 1968; Navarrete Linares, 2002).

Resumirei agora as principais técnicas e procedimentos "xamânicos" utilizados no processo de criação, ou melhor, de fabricação, do sol 4-movimento e da humanidade que vivia nele, presentes nas histórias contadas pelos Mexica e outros povos mesoamericanos. ${ }^{3}$ Para começar, é importante assinalar que as diversas versões não esclarecem de maneira definitiva a identidade dos seres que fabricaram o cronotopo solar. Alguns são chamados teotl, deuses, mas outros, simplesmente tlácatl, pessoa em náhuatl, um substantivo que se refere a seres com alto grau de agentividade, com rosto para se expressar e com olhos para ver, nem sempre humanos (Bassett, 2015). De fato, como veremos, a distinção clara entre deuses e homens foi produto do processo de fabricação do novo sol e de seu espaço-tempo, e não seu antecedente.

As versões coincidem na afirmação de que o mundo vivia na escuridão após a destruição do sol anterior (que pode ter sido devorado por feras ou incinerado por uma chuva de fogo, ou destruído pelo vento) e do desaparecimento da humanidade anterior (transformada em peixes, macacos ou aves). Nesta escuridão, os fabricantes do novo sol se reuniram em um lugar chamado Teotihuacan (em náhuatl "lugar onde os seres se transformam em deuses"). Dois deles se apresentaram como voluntários para se transformarem no novo astro: um deus, téotl, orgulhoso e rico, Tecuciztécatl e uma pessoa, tlácatl, enferma, anciã e pobre, Nanahuatzin. Ambos subiram ao topo de antigos templos em forma de pirâmides (que eram também tumbas dos reis, e casas dos deuses de sóis anteriores) e realizaram ao longo de quatro noites um complexo ritual chamado macehualizțti, merecimento ou penitência, uma cerimônia pensada para obter favorecimento de forças mais poderosas e para realizar uma transformação dos seres que participam nela. As oferendas que realizou Tecuciztécatl durante este ritual foram todas luxuosas e opulentas; as de Nanahuatzin, por sua vez, foram pobres e humildes.

Ao final deste período, os demais seres acenderam uma imensa e ardente fogueira para que os dois penitentes se jogassem nela e emergissem transformados em sol. O vaidoso téotl Tecuciztécatl vacilou três vezes sem se jogar; a pessoa Nanahuatzin, por sua vez, precipitouse ao fogo sem hesitação e saiu dele como novo sol. Invejoso, o deus saltou após ela nas 
chamas e também surgiu transformado em astro luminoso. Para distingui-los, os outros deuses projetaram um coelho no rosto do segundo sol, apagando seu brilho, transformando-o na lua. Nem o sol e nem a lua, podiam, entretanto mover-se no céu. Desesperados, os deuses se perguntaram: "Como viveremos? O sol não se move. Por acaso viveremos confundidos com os macehualtin [humanos]? Que assim seja: para que por meio de nós reviva, morramos todos nós” (Sahagún, 1950-70: v. 7, 7).

De imediato, Éhecatl, o senhor do vento, se encarregou de matar todos os deuses. No entanto, nem estas mortes puderam colocar o sol e a lua em movimento. Somente os moveu o vento poderoso do deus Ehécatl e desde então o sol e a lua se movem regularmente pelo céu no marco de cronotopo solar.

A humanidade que iria viver sob este novo sol foi fabricada por este mesmo personagem, sob um outro nome, Quetzalcoatl, a serpente emplumada. Segundo os relatos, os outros "deuses" encarregaram Quetzalcoatl a empreender uma perigosa viagem ao inframundo para recuperar os ossos das humanidades anteriores. $\mathrm{Na}$ terra dos mortos, realizou seu pedido ao temido Mictlantecuhtli, o senhor do lugar. Este concordou em lhe entregar os ossos, mas pediu que antes o visitante fizesse música com um caracol que não estava perfurado, de maneira que não poderia fazer som algum. Consciente da armadilha, Quetzalcoatl pediu a um verme que perfurasse a concha e chamou os insetos para zumbirem em seu interior.

Derrotado por essa armação, Mictlantecuhtli não teve opção senão deixá-lo recolher as antigas ossadas, mas pediu que Quetzalcóatl as trouxesse de volta. O visitante tornou a enganá-lo, pois atou os ossos em um envoltório sagrado para levá-los para sempre do Mictlan. Ao descobri-lo, o senhor dos mortos mandou cavar um buraco, no qual caiu Quetzalcoatl. Os ossos que levava se quebraram em fragmentos irregulares e foram bicados por codornas que participavam do plano do senhor da morte. Conformado com esse revés, o deus do vento levou os restos dos esqueletos até onde estavam seus companheiros. Ali, a deusa Quilaztli moeu os ossos em uma pedra de moer, idêntica a que se usa para preparar a massa do milho para comer, e logo os deuses varões regaram o pó o misturaram com o sangue extraído de seus próprios pênis. Com a massa resultante fabricaram aos seres humanos que viveriam sob o sol 4-movimento.

O relato é concluído com uma frase significativa, atribuída às pessoas que o contavam em tempos antigos: "Pelos deuses nasceram os macehualli, porque eles fizeram macehualiztli por nós" (Leyenda de los soles, 2002: 181). 
Em outras palavras, os seres humanos, nomeados macehualli (objeto e produto do verbo maceua), "merecidos" são produto de um ato de merecimento, macehualiztli (penitência, oferenda), dos seres que os criaram. Em troca, veremos, eles devem fazer macehualiztli em homenagem a seus criadores.

\section{Xamanismo, não teogonia}

A imensa maioria dos estudiosos até hoje tem interpretado estes relatos sobre a fabricação do sol e dos humanos como mitos cosmogônicos, protagonizados por deuses poderosos que criaram o mundo, ao modo das teogonias clássicas de Hesíodo e de Ovídio. Este modelo fora imposto já desde o século xvi pelos freis cristãos, empenhados em reduzir as práticas cosmopolíticas indígenas ao modelo da religião pagã clássica. Minha proposta é, entretanto, interpretar estas histórias como descrições de técnicas xamânicas que foram utilizadas para efetuar uma transformação da realidade e fundar um novo cronotopo, o cronotopo solar, que incluía uma nova hierarquia ontológica dos entes que viviam nele. Essas ações foram realizadas por seres que transcenderam os umbrais entre o humano e o divino ao tempo que estabeleceram relações de definição ontológica mútua entre estes dois tipos de seres e de intercâmbio recíproco entre eles.

Para começar, deve ser destacado que os lugares nos quais se realizaram estas passagens, Teotihuacan e o subterrâneo Lugar dos Mortos, eram precisamente lugares que pertenciam ao cronotopo terrestre da montanha, em que se dissipavam as distinções entre seres humanos, divindades, mortos e vivos. As histórias mexicas contam que o "lugar onde se fazem os deuses" estava cheio de edifícios tracualli, "coisa fechada" em náhuatl, que eram antigas pirâmides feitas pelos humanos de um sol anterior que, por seu tamanho, pareciam montes naturais, portanto análogos a Colhuacan, ou Monte Curvado, de Aztlan. Estes objetos fabricados apagavam a distinção entre natureza e cultura, entre o dado e o feito e, por isso, permitiam acesso ao cronotopo terrestre da montanha e a seu tempo imanente. Dessa maneira efetuavam mudanças ontológicas e temporais nos seres que a eles acediam: deuses e pessoas podiam viraram sol e lua, uma nova humanidade foi fabricada ou "merecida" por Quetzalcóatl e seus colegas a partir dos ossos das velhas humanidades.

A própria dificuldade da tarefa que empreenderam é importante. Como outros relatos ameríndios de fabricação cósmica, esta história enfatiza a relativa falta de poder e de 
conhecimento dos seres encarregados de formar o cosmos. Sua agência é limitada e sempre está submetida à aprovação e colaboração de outros atores, assim como aos potenciais dissensos e mesmo sabotagens. Além disso, suas ações têm resultados incertos e os "criadores" estão forçados a realizar ensaios repetidos e falidos até alcançarem a configuração cósmica desejada, que muitas vezes é desconhecida de antemão, pois é "encontrada", por assim dizer, no mesmo processo de transformação, ou melhor, é o produto da confluência das vontades dos diferentes atores envolvidos e de suas distintas vontades, capacidades e poderes.

Por outro lado, as fabricações e transformações cósmicas descritas nestes relatos envolviam a utilização de técnicas "cotidianas", muito semelhantes às que empregavam os seres humanos para transformar o mundo ao seu redor: acender uma fogueira para queimar e cozinhar, utilizar uma pedra de moer para fazer massa, umedecê-la com um líquido, oferecer sangue, realizar rituais de merecimento ou macehualiztli.

A diferença entre as ações dos seres ativos no início do cronotopo solar e as dos humanos que viviam dentro dele era apenas de "magnitude", retomando o conceito de Latour (1993: 158-161). Quer dizer, radicava no tamanho da rede de seres e atores que cada um deles era capaz de mobilizar e não que fossem de uma natureza qualitativamente distinta, seja divina ou humana, ritual ou técnica, simbólica ou efetiva, mítica ou histórica. A magnitude dependia, por sua vez, do próprio cronotopo: os primeiros seres fabricaram-no e, nesse mesmo ato, transformaram-se em deuses (pois, como eles mesmos disseram: "não queriam confundir-se com os macehualli, os humanos"). Os seres humanos de tempos posteriores podiam atuar então unicamente dentro do marco desse espaço-tempo construído, como nos demonstra o relato do retorno a Aztlan: sua existência somente tinha validade dentro do marco do cronotopo fabricado por seus criadores.

As diferenças ontológicas entre homens e deuses, e também outros tipos de seres, eram essencialmente relacionais e somente tinham vigência dentro do cronotopo particular. No começo, os deuses se fizeram macehuani, merecedores (sujeitos ativos do verbo macehua), ao realizar a ação técnica e ritual do macehualiztli e fabricar o sol e os seres humanos, por isso estes foram seus macehualli, merecidos. Por sua vez, os humanos deviam fazer seu próprio macehualiztli para confirmar sua própria existência e manter vivos os deuses, em seu caráter de macehuani. Nenhum dos dois tipos de seres podia existir independentemente desta relação. 


\section{A cosmopolítica mexica entre horizontalidade e hierarquia}

O modelo teogônico-religioso que tem geralmente sido empregado para interpretar os relatos nahuas e mexicas de criação desde o século Xvi até o presente, tende a enfatizar as diferenças verticais absolutas entre deuses e humanos, entre criadores e criaturas. A religião, entendida no sentido mediterrânico do termo, seria encarregada de mediar as relações entre eles, por meio de instrumentos de relação desigual e subordinada, como o sacrifício, a oferenda, a penitência. Entretanto, a interpretação xamânica que proponho nos permite imaginar um cosmos mais dinâmico e transversal, em que as fronteiras entre deidades, seres humanos e outros entes são muito mais fáceis de atravessar e no qual as relações entre eles são de natureza cosmopolítica, mediadas por rituais e técnicas que podem ser ao mesmo tempo horizontais e recíprocas, mas também verticais e hierárquicas.

Utilizo aqui o termo "cosmopolítica" seguindo a definição chave de Isabelle Stengers (2005): como uma relação política que não dá por fixa e prévia a definição da realidade, isto é, de um mundo único e real, mas constrói seus próprios mundos, sempre plurais, no próprio processo político. Estas práticas cosmopolíticas também não distinguiam, como faz o modelo clássico de religião, entre atos materiais e sociais e atos sobrenaturais e religiosos. A complexa trama de relações e intercâmbios diplomáticos que os Mexica construíram com seus deuses e com sua "natureza" abarcava todas estas dimensões ao mesmo tempo.

\section{Intercâmbios horizontais}

No cronotopo solar, os deuses intervinham de maneira constante na vida social e humana. Para começar, se faziam presentes em envoltórios sagrados que eram carregados pelos seres humanos e viviam a seu lado (Olivier, 1995). Também tomavam posse de ixiptlas, ou "imagens vivas" que eram seres humanos e animais que os encarnavam e atuavam como eles (Hvidtfelt, 1958). Igualmente, habitavam "imagens" de pedra, madeira ou sementes fabricadas pelos artistas. Esta materialidade lhes permitia atuar no tlaltícpac e interagir com os seres humanos e outras criaturas. Sob essa forma material também podiam ser e frequentemente eram "sacrificados", quer dizer, mortos de maneira ritual, devorados e transformados (Graulich, 2005).

Os demais seres do tlaltícpac, viventes e não viventes, começando pelas pessoas, também podiam transpor as distinções ontológicas que os separavam. Os humanos podiam realizar rituais de macehualiztli para se transformarem em deuses, de maneira temporária 
ou definitiva, antes ou depois de sua morte, fosse como "ixiptla" ou como homem-deus. Este é um termo chave da antropologia histórica mesoamericana, que foi emprestado do trabalho de Alfred Métraux (1931) nas terras baixas da América do Sul. Eram pessoas que se transformavam em recipientes físicos de uma força ou vontade divina e que, como tais, regiam o destino de um grupo humano (López Austin, 1973). Existiam também os nahuales, pessoas que podiam assumir a forma física de outros seres vivos, de forças naturais; até mesmo alguns deuses se nahualizavam em animais e seres humanos.

Isto significava que a distinção entre deuses e humanos (e animais, sem dúvida) não era absoluta nem estática, por mais que houvesse sido definida ontologicamente no princípio do cronotopo solar. Os diversos tipos de seres transcendiam as fronteiras que os separavam com diversos fins. Esta "confusão" era particularmente evidente e perigosa em âmbitos liminares como os caminhos noturnos ou os lugares "encantados", onde a ordem solar enfraquecia - e era frequente que as pessoas se encontrassem com seres cuja identidade não podiam reconhecer de maneira imediata, o que os colocava em grave perigo (Burkhart, 1989). Igualmente, quando o sol se ocultava por um eclipse, ou pelo final de um ciclo de 52 anos, as distâncias entre os seres do tlaltícpac e dos habitantes de outros âmbitos se atenuavam e havia perigosas ameaças que podiam destruir o próprio cronotopo solar (Soustelle, 1956: 107-108).

\section{A construção cosmopolítica da hierarquia}

Em contrapartida, as "forças da ordem", se assim podemos chamá-las, procuravam manter, reafirmar estas distinções e criar uma hierarquia o mais estável possível. O próprio sol, com sua luz, seu calor e seu movimento regular, ordenava o espaço-tempo e mantinha separados os diversos tipos de seres. O seu movimento estava no centro do complexo sistema dos calendários, uma sucessão intricada de tempos e espaços que regiam as ações e os relacionamentos das deidades, dos seres humanos e de todos os outros seres do mundo (Díaz Alvarez, 2013).

Outros princípios de hierarquização e ordem fundamentais eram a estratificação social, a centralização política e o controle dos aparatos oficiais sobre as ações cosmopolíticas. Manter as distinções de poder e a hierarquia de forças no seio do que chamamos a sociedade, era uma tarefa inseparável do imperativo de preservar a ordem cósmica, pois ambos existiam amalgamados, um dentro do outro, sem as distinções que estamos acostumados a fazer. A cosmopolítica construía a hierarquia cósmica, ao mesmo tempo da hierarquia social. 
Para começar, os rituais de macehualiztli, que antes da criação haviam servido para que os seres criadores do cosmos se transformassem em sol, lua e deuses, e para que fabricassem os seres humanos, foram utilizados também no contexto do cronotopo solar para ratificar performativamente as diferenças entre as pessoas e as deidades, e também entre os seres humanos. Pelo fato de assumir a posição de penitentes, ou macehualli, os atores humanos confirmavam em seus feitos sua subordinação frente aos atores divinos, os macehuani. Ao mesmo tempo, a ordem social hierárquica limitava o número de pessoas que podiam iniciar estes rituais e obter a "bendição" ou o "favor" divino. Por isso, um princípio chave de hierarquização entre humanos era a prática de técnicas corporais que os freis católicos chamaram "penitência", inspirados por suas próprias noções da corporalidade e sua relação com a alma imortal. Os estratos superiores da sociedade mexica praticavam com mais afinco os jejuns alimentícios e sexuais, as práticas de sofrimento como tomar banho em água fria e a privação do sono, a extração contínua de sangue do pênis, braços, dobra da perna e da língua (Romero García, 1995).

Segundo a interpretação mais utilizada, este “asceticismo" era uma forma de expiação das faltas ou pecados e uma justificativa ideológica de seu privilégio social. Podemos propor que estas práticas permitiam que as pessoas de maior hierarquia social assumissem o papel de macehuani frente a outras pessoas de menor hierarquia, que ficariam reduzidas a macehualli frente a elas. Ao mesmo tempo, confirmavam seu papel de seres humanos, macehualli, em relação às deidades, macehuani. Desta maneira, o macehualiztli construía a hierarquia social e mantinha em funcionamento a hierarquia cósmica.

O exemplo mais claro e eloquente desta hierarquização ontológica e social era o caso rituais de "coração" dos governantes. Neles o ser humano que acedia ao poder era transformado por um longo programa ritual de macehualiztli que culminava na morte de sua identidade humana anterior. Logo renascia de maneira espetacular com uma nova identidade de tlatoani, um homem divinizado, ou melhor, um ser colocado em uma posição intermediária entre os seres humanos e os deuses (Olivier, 2015). O mesmo título que tinha o governante, aquele que fala, o definia como um interlocutor de ambas as categorias do ser, o ápice e dobradiça da cosmopolítica mexica.

Outra categoria essencial de ações cosmopolíticas que vinculavam humanos, deidades e outros seres eram as diferentes formas de predação, manifestas na caça, na guerra e no "sacrifício" humano, ou para ser mais exato, o tlacamictiližtli, matança de gente, como o nomeavam os antigos nahuas. Não é este o contexto para desenvolver uma interpretação 
FEDERICO NAVARRETE LINARES. ENTRE A COSMOPOLÍTICA E A COSMOHISTÓRIA: TEMPOS FABRICADOS...

mais detalhada destas práticas, uma tarefa que ainda não está completa. Neste texto só apresentarei algumas indicações gerais baseadas nas propostas recentes de colegas como Alejandro Fujigaki Lares (2015) e Guilhem Olivier (2010), além das minhas próprias pesquisas (Navarrete Linares, 2011b).

As relações de predação construíam uma complexa rede de intercâmbios horizontais e hierárquicos, que criavam e mantinham por sua vez, diferenças e identidades compartilhadas, laterais e verticais. As distinções entre presa e predador, comida e comedor, morto e matador eram essencialmente relacionais, e todo ser, humano ou não, podia ocupar uma ou mais destas posições em diversos momentos e, às vezes, ao mesmo tempo. No tlacamictiliztli de guerreiros inimigos, para mencionar o exemplo mais conhecido, era enfatizada a identificação ontológica entre o sacrificante e o sacrificado (Clendinnen, 1985). O guerreiro que havia tomado como prisioneiro um combatente rival o levava a viver em sua casa e o transformava em parente. Os rituais prévios ao assassínio enfatizavam a incorporação do antigo inimigo à pessoa de seu captor e ao conjunto de sua comunidade. Deste modo, após a morte deste último, dizia-se que o próprio sacrificante havia sido morto (e purificado) e ele se negava a comer a carne do sacrificado, pois seria como comer a si mesmo (Graulich, 2005).

Este é um exemplo clássico de alteridade constitutiva, entre dois grupos de seres humanos, surpreendentemente similar ao complexo guerreiro-canibalístico dos Tupi da costa, tal como foi interpretado por Florestan Fernandes (1952) e Eduardo Viveiros de Castro (2002a). Uma relação similar deve ter existido entre pessoas e deidades. Ainda que as fontes não mencionem esse aspecto (pois nelas impera a visão religiosa e vertical do assassínio ritual), podemos inferir que os deuses que comiam humanos sacrificados absorviam algo de sua natureza ou ao menos ocupavam seu ponto de vista dentro das relações cosmopolíticas. O mesmo parece haver ocorrido quando um jovem galante se transformava em Tezcatlipoca ou uma bela donzela em Xochiquetzal: os seres humanos ingeriam a carne destes deuses após seu sacrifício e, assim, se apropriavam de maneira literal de muitas de suas forças e podiam olhar e agir como deuses. As relações entre humanos e animais mediadas pela caça não eram tão diferentes e era frequente que o caçador assumisse a posição de presa, particularmente do veado, transformado em vítima sacrificial por excelência.

Outra dimensão importante destas práticas, como as do complexo canibalístico tupi, é a construção da temporalidade; no caso mexica isto quer dizer manter o funcionamento do cronotopo solar. Esta função cósmica do sacrifício é bem conhecida e tem sido interpretada como indício de uma ideologia milenarista mexica (Caso, 1953). Parece-me importante 
assinalar que essas relações também davam impulso à narrativa geral da história do povo e de seu deus Huitzilopochtli. O constante intercâmbio de alteridades constitutivas, a ingestão sucessiva de gerações de inimigos, de presas e de predadores, construía também uma temporalidade humana, uma história orgulhosamente particular, mas também ancorada em identidades compartilhadas.

Uma contrapartida complementar às relações de predação e ingestão eram as relações de intercâmbio cerimonial altamente formalizadas, que criavam um fluxo constante de pessoas e sangue, bens culturais e tecnologias, identidades e afiliações dinásticas (Navarrete Linares, 2011a). Essas relações pacíficas estavam sempre acompanhadas pela ameaça ou pela realidade da guerra. Ambas construíam hierarquias ao mesmo tempo em que permitiam a absorção constitutiva das alteridades.

\section{A imposição do monopólio mexica}

No marco do cronotopo do sol 4-movimento, entretanto, pode-se sugerir que os Mexica outorgaram a si mesmos um papel centralizador e dominante no manejo desses intercâmbios e transformações. Deste modo, trataram de transformar as relações transversais (relativamente horizontais ou, pelo menos, dinamicamente verticais) de intercâmbio predatório de carne, sangue e vida, e dos intercâmbios cerimoniais, num sistema hierárquico mais estável. Ao definir sua capital, México-Tenochtitlan como o centro cósmico e sacrificial supremo, tentaram se colocar no ápice de todas essas redes e as dirigiram para um fluxo mais vertical e centralizador.

Isso tensionou as relações recíprocas de alteridade constitutiva com as outras entidades cosmopolíticas, os povos aliados e inimigos, pautadas pela guerra e pelo intercâmbio cerimonial. A metrópole impôs uma apropriação unilateral e não recíproca dos corpos, as identidades e as forças dos centros dominados, matando seus guerreiros, tomando como cativos seus deuses, controlando as redes de intercâmbio cerimonial e comercial e apropriando-se do prestígio de antigos centros cósmicos, como Teotihuacan ou Tollan. Isto produziu um descontentamento entre as demais entidades políticas que irrompeu com a chegada dos conquistadores espanhóis (Conrad, 1988).

A cosmopolítica mexica pode ser, então, compreendida como a permanente e nunca acabada construção de uma hierarquia fixa, ontológica e cósmica, e também social, econômica e política, em um cosmos e uma arena social definidos sempre por dinâmicas 
horizontais de transformação e alteridade constitutiva entre os diferentes tipos de seres e grupos humanos. Para alcançá-la, os governantes de México-Tenochtitlan se apropriaram das técnicas xamânicas transversais do nahualismo e do macehualiztli e as transformaram em geradoras de relações verticais, modificando também a lógica horizontal das relações de predação e de intercâmbio cerimonial num sentido hierárquico.

\section{A cosmohistória, ou como viver num pluriverso}

Depois desta análise, torna-se claro que a embaixada enviada pelo tlatoani Moteuhczoma Ilhuicamina a Aztlan fracassou porque foi de encontro com os limites ontológicos, temporais e espaciais da hierarquização cósmica e social construída pela cosmopolítica mexica. Ao enviar sua embaixada a Aztlan, o poderoso tlatoani tinha a intenção de estender a pulsante rede hierárquica de macehualiztli e predação centrada em sua pessoa, seus exércitos, e a cidade de México-Tenochtitlan, ao lugar de origem de seu deus e seu povo, um espaço tão remoto como já passado, desde sua perspectiva particular.

Esta era uma manobra cosmopolítica muito frequente entre os governantes mesoamericanos. Por exemplo, os reis maias do chamado período clássico gostavam de estabelecer relações de intercâmbio e de identidade com os deuses e os reis fundadores de suas dinastias que haviam criado o mundo milhões de anos antes deles. Esta "conquista" do passado era acompanhada frequentemente por uma "conquista" do futuro, pois prometiam estender seu poder até tempos igualmente distantes no porvir (Bernal Romero, 2011). De maneira análoga, podemos supor que, ao restabelecer as relações cordiais de intercâmbio entre Huitzilopochtli e sua mãe, Coatlicue, Moteuhczoma procurava não somente pagar uma dívida pendente com o passado, mas também ativar uma relação de intercâmbio e subordinação que seria benéfica ao futuro.

Seu fracasso dramático deveu-se à superestimação da extensão de seu poder cosmopolítico. O que aprenderam seus embaixadores em Aztlan foi precisamente que o lugar de origem de seu povo e de seu deus patrono não era e nem podia se converter em "seu passado", no sentido de uma realidade temporal que podiam integrar e subordinar ao fluxo histórico do devir particular dos Mexica. Diferentemente, esse lugar e os seres que o habitavam estava fora de seu alcance, além de seu espaço-tempo e de sua realidade, no cronotopo terrestre da montanha. Pelo mesmo motivo, aprenderam que tampouco podiam tornar Aztlan em parte 
de seu futuro, pois a continuada existência do seu cronotopo diferente era a demonstração inescapável da finitude e da inevitável destruição de seu próprio cronotopo solar.

O relato nos deixa claro que Aztlan permanecia fora do cosmos mexica e que nela não existiam, nem tinham vigência as hierarquias sociais e ontológicas construídas por sua cosmopolítica. Por isso, nem o poderio dos exércitos, nem as riquezas do tlatoani, nem a glória do deus Huitzilopochtli tinham eficácia alguma nesse lugar. Isso explica a total indiferença que sente Coatlicue diante das vitórias de seu filho, o deus Huitzilopochtli e dos seres humanos que o servem. Vistos desde fora, o poder e a riqueza mexica, todas as verticalidades construídas por sua cosmopolítica, se revelavam unicamente produtoras da temporalidade e da morte dentro de seu cronotopo particular.

As humildes sandálias que Coatlicue enviou de volta a seu filho Huitzilopochtli eram a negação explícita das hierarquias e verticalidades construídas pela cosmopolítica mexica. Por outro lado, suas profecias a respeito da inevitável queda de seu poderio demonstravam que toda a hierarquia social e cósmica estava por necessidade limitada ao cronotopo artificial em que havia sido produzida e estava condenada a desaparecer com ele.

Em termos da teoria contemporânea, o que os Mexica descobriram nesta viagem desafortunada foi que habitavam um pluriverso e que para transitar de um a outro de seus mundos incomensuráveis tinham que praticar o que chamo de cosmohistória. O conceito de pluriverso, tal como desenvolvido por Bruno Latour (2002), me parece idôneo para compreender a multiplicidade de realidades e cronotopos, de hierarquias ou heterarquias ontológicas, de práticas políticas e cosmopolíticas com que estamos lidando. O que temos, portanto, é uma pluralidade de universos que convivem e se sucedem em temporalidades descontínuas. Estes pluriversos se comunicavam entre si por meio de umbrais perigosos (Coatépec, o Monte das serpentes, o Chicomóztoc, o Lugar das Sete Cavernas, Colhuacan, o Monte curvado, Teotihuacan, Onde os seres se fazem deuses, o Mictlan, Lugar dos mortos) que poderiam ser atravessados por seres que soubessem utilizar as técnicas xamanísticas do nahualismo ou do macehualiztli. Porém, não constituíam um cosmos ordenado, pois não compartilhavam uma ontologia, nem um cronotopo universal ou comum. Por isso mesmo, as hierarquias ontológicas de deuses, homens e outros seres e as intrincadas redes de relações de macehualiztli, de guerra/predação e de intercâmbio cerimonial entre eles somente tinham validade no marco de seu cronotopo específico.

Neste sentido, para retomar e talvez abusar um pouco das propostas de Viveiros de Castro, poderíamos propor também que as relações entre estas multinaturezas também são 
necessariamente perspectivistas (Viveiros de Castro, 2002b). Quando os relatos da fabricação do sol nos contam que os seres humanos dos sóis anteriores se transformaram em peixes, macacos ou tigres, talvez afirmem que assim é como as pessoas do cronotopo solar atual as podem ver, pois não pertencem a seu espaço-tempo, nem à sua hierarquia ontológica. Por isso, não poderia ser descartado que em seu outro cronotopo eles continuem sendo humanos e vejam a nós como outros tipos de seres, animados ou não. Este perspectivismo, ancorado num cronotopo específico e numa corporalidade particular, é evidente no falho intercâmbio entre os Mexica de Tenochtitlan e os povoadores de Aztlan. Em seus diálogos, fica claro que a velhice e a morte não são absolutas, mas sim relativas ao tempo-espaço em que está inserido cada ser, segundo o peso ou leveza de seu corpo.

Para concluir, gostaria de perguntar o seguinte: se a cosmopolítica mexica não foi capaz de incorporar e menos ainda subordinar Aztlan a suas redes, que tipo de relação se estabeleceu entre ambas as cidades e seus habitantes? Minha resposta seria que se tratou aí de uma relação cosmohistórica. Como assinalou Stengers, a cosmopolítica, e portanto a cosmohistória, se opõem necessariamente à política e à História cosmopolita moderna, definida por Kant (1987), que parte da premissa de que existe um único mundo natural e humano com um só cronotopo, que são o produto direto da realidade física do espaçotempo e da evolução biológica da humanidade (Stengers 2005: 994). Esta convicção unitária foi, por dois séculos, a contrapartida e a âncora do relativismo cultural antropológico, cujos limites ontológicos eram precisamente a impossibilidade de subverter a unicidade da história da evolução da "humanidade" e de seu tempo linear.

Como ela começou para os embaixadores mexicas na viagem a Aztlan e a dolorosa consciência dos limites do seu cronotopo solar, nossa cosmohistória começa precisamente onde termina essa visão unitária do mundo e do espaço-tempo. Ela nasce do reconhecimento da existência de um pluriverso histórico integrado por muitos mundos socionaturais particulares, cada um com seus cronotopos irredutíveis. Isto é muito parecido com a relatividade histórica geral que nos propôs Lévi-Strauss há meio século em seu "profético" ensaio Race et histoire, uma espécie de viagem a Aztlan que gerou a mesma falta de compreensão de parte da história hegemônica moderna (Lévi-Strauss 2001). De fato, apenas conseguimos entendê-lo agora, quando nosso próprio mundo histórico, moderno e unitário, ancorado em seu tempo tão linear e suas ciências tão poderosas, está numa crise que parece ser terminal e que tem sido assinalada por autores como Reinhardt Koselleck (1989) e François Hartog (2003). Neste novo horizonte, o tempo único e linear se dissolve 
em uma pluralidade de passados e presentes, uma fractalidade de realidades conflituosas, rebeldes a qualquer harmonização (Mudrovcic, 2013).

Para nos aproximar dos múltiplos cronotopos mesoamericanos e sua pluralidade de historicidades, não podemos nos nahualizar, lamentavelmente. Mas podemos, por outro lado, aprender sobre a diplomacia praticada pelos enviados do poderoso tlatoani mexica e reconhecer que, quando nos comunicamos com um mundo histórico diferente, devemos começar por tentar compreender seu espaço-tempo e sua organização ontológica particulares, sem impor-lhe nossas concepções sobre a temporalidade e a realidade, que já não podemos considerar universais. Também devemos aceitar que as "verdades" que pudermos extrair dessas conversações diplomáticas, como proposto por Marisol de la Cadena (2010) na sua interpretação do conceito de cosmopolítica, serão sempre produto de negociações e estarão inevitavelmente infestadas de equívocos e mal entendidos e nunca serão uma referência simples a uma realidade comum e única.

O relato de Aztlan nos lembra também que a cosmohistória não é uma invenção de nossa modernidade em crise. Em realidade, existe pelo menos há mais de quinhentos anos, longos séculos de encontros, guerras e diplomacia, de mudanças ecológicas e epidemias, de intercâmbios entre os povos ameríndios, africanos e europeus, que chegaram às margens de nosso continente, e de outros também (Navarrete Linares, s.d.). A partir desta perspectiva, também podemos compreender o relato de retorno a Aztlan como uma premonição da conquista espanhola, mas não nos termos proféticos do tempo linear da nossa história. Trata-se, ao contrário, de uma antecipação das complexas negociações cosmohistóricas que os Mexica realizaram com os invasores espanhóis, da diplomacia que construiu o pluriverso histórico em que vivemos desde então, mesmo sem nos darmos conta. Trata-se também de um guia para que possamos aprender a viver também na cosmohistória em nosso presente e construir um futuro mais plural.

Tradução de Ana Cristina de Vasconcelos Lima e Eduardo Natalino dos Santos 


\section{Notas}

${ }^{1}$ Este artigo é uma versão modificada da "Conferência Nimuendaju” (Centro de Estudos Ameríndios) proferida em 17 de março de 2016 na Universidade de São Paulo.

${ }^{2}$ Sei que xamanismo é uma palavra com muitos significados, mas neste caso eu proponho utilizá-la para me referir a agentes humanos e não-humanos que se transformam para agir em diferentes realidades cósmicas e que praticam algum tipo de cosmopolítica (Viveiros de Castro, 2008).

${ }^{3}$ Os relatos que analiso são conhecidos como La leyenda de los soles (2002), Historia de los mexicanos por sus pinturas (2002), Anales de Cuaubtitlan (1992) Histoyre du Mechique (2002) e a história do origem do Sol e a Lua na Historia General de las Cosas de la Nueva España (Sahagún, 1950-70: v. 7, 3-8).

\section{Referências bibliográficas}

\section{Anales de Cuauhtitlan}

1992 “Anales de Cuauhtitlan”. Códice Chimalpopoca. Anales de Cuaubtitlan y Leyenda de los Soles. Velázquez. Trad. Primo Feliciano, México, unAm/in Históricas, pp. 3-68.

Bassett, Molly H.

2015 The Fate of Earthly Things. Aztec Gods and God-Bodies. Austin, University of Texas Press.

Bernal Romero, Guillermo

2011 El señorio de Palenque durante la era de K'inich Janaabb' Pakal y K'inich Kan B'ablam (617-702 d.C.). México, tese, Universidad Nacional Autónoma de México.

BURKHART, Louise

1989 The Slippery Earth: Nabua-Christian Moral Dialogue in Sixteenth-Century Mexico. Tucson, University of Arizona Press.

CAso, Alfonso

1953 El pueblo del Sol. México, Fondo de Cultura Económica.

Clendinnen, Inga

1985 "The Cost of Courage in Aztec Society". Past and Present, 107: 44-89. 
Conrad, Geoffrey W. e Demarest, Arthur

1988 Religión e Imperio. Dinámica del expansionismo ąteca e inca. Madrid, Alianza Editorial.

DE la Cadena, Marisol

2010 "Indigenous Cosmopolitics in the Andes: Conceptual Reflections beyond 'Politics”'. Cultural Anthropology, 25, 2: 334-370.

Díaz Álvarez, Ana

2013 "Tlapohualli, la cuenta de las cosas. Reflexiones en torno a la reconstrucción de los calendarios nahuas". Estudios de Cultura Nábuatl, 46: 159-197.

Durán, Diego

1995 Historia de las Indias de Nueva España e Islas de Tierra Firme. México, Consejo Nacional para la Cultura y las Artes.

Fujigaki LARes, José Alejandro

2015 La disolución de la muerte y el sacrificio. Contrastes de las máquinas de transformaciones y mediaciones de los rarámuri y los mexicas. México, tese, Universidad Nacional Autónoma de México.

Graulich, Michel

2005 Le Sacrifice bumain chez les Aztèques. Paris, Fayard.

HARTOG, François

2003 Régimes d'historicité-Presentisme et experiences du temps. Paris, Éditions du Seuil.

Historia DE LOS MEXICANOS POR SUS PINTURA

2002 "Historia de los mexicanos por sus pinturas". Mitos e historias de los antiguos nahuas. Trad. Rafael Tena, México, CNCA, pp. 15-111.

Histoyre du Mechique

2002 "Histoyre du Mechique". Mitos e historias de los antiguos nabuas. Trad. Rafael Tena, México, CNCA, pp. 123-165. 
FEDERICO NAVARRETE LINARES. ENTRE A COSMOPOLÍTICA E A COSMOHISTÓRIA: TEMPOS FABRICADOS...

HvidTFELt, Arild

1958 Teotl and Ixiptlatli. Some Central Conceptions in Ancient Mexican Religion. With a General Introduction on Cult and Myth. Copenhagen, Munksgaard.

KANT, Immanuel

1987 "Ideas para una historia universal en clave cosmopolita". Ideas para una historia universal en clave cosmopolita y otros escritos sobre Filosofía de la bistoria. Madrid, Editorial Tecnos, pp. 3-23.

KoselLeCK, Reinhart

1989 [1979] Vergangene Zukunft. Zur Semantik geschichtlicher Zeiten. Frankfurt am Main, Suhrkamp Verlag.

Latour, Bruno

1993 Nunca hemos sido modernos: ensayo de antropología simétrica. Madrid, Debate.

2002 War of the Worlds: What about Peace? Chicago, Prickly Paradigm Press.

LÉVi-STRAuss, Claude

2001 'Race et histoire". Race et histoire. Race et culture. Paris, Bibliothèque Albin MichelUnesco, pp. 29-120.

LEYENDA DE LOS SOLES

2002 "Leyenda de los soles". Mitos e bistorias de los antiguos nabuas. Trad. Rafael Tena, México, CNCA, pp. 167-206.

López Austin, Alfredo

1973 Hombre-Dios. Religión y política en el mundo nábuatl. México, D.F., UNAM/IIH.

2009 Monte Sagrado-Templo Mayor. México, Universidad Nacional Autónoma de México-

Instituto de Investigaciones Antropológicas, Instituto Nacional de Antropología e Historia.

MARTÍNEZ, Roberto

2011 El nahualismo. México, Instituto de Investigaciones Históricas-Universidad Nacional Autónoma de México. 
MÉtraux, Alfred

1931 “Les Hommes-Dieux chez les Chiriguano et dans l'Amérique du Sud”. Revista del Instituto de la Universidad Nacional de Tucumán, 2: 61-91.

Moreno de los Arcos, Roberto

1968 “Los cinco Soles cosmogónicos”. Estudios de Cultura Nábuatl, 7: 183-210.

Mudrovcic, María Inés

2013 "Cuando la historia se queda con el presente o lo que queda del "pasado histórico"”. In Mudrovcic, María Inés e RABOtNikof, Nora (orgs.), En busca del pasado perdido. Temporalidad, historia y memoria. México, Siglo xxi Editores-Instituto de Investigaciones Filosóficas, UNAM, pp. 66-87.

\section{Navarrete Linares, Federico}

s.d. "Historia mundial y cosmohistoria". In Riojas, Carlos e RinKe, Stefan (orgs.), ¿Historia global, historia por áreas o historia nacional? Tensiones y nuevas pespectivas. Berlim, Asociación de Historiadores de América Latina-Freie Universität.

1999 "Nahualismo y poder: reflexiones sobre un viejo binomio mesoamericano". In Olivier, Guilhem e Navarrete, Federico (orgs.), El héroe entre el mito y la historia. México, Instituto de Investigaciones Históricas-Cemca, pp. 155-179.

2002 "Vivir en el universo de los nahuas". Arqueología Mexicana, 10 (56): 30-35.

2011a "Chichimecas y toltecas en el Valle de México". Estudios de Cultura Nábuatl, 42: $19-50$

2011b "Para pensar las funciones del sacrificio humano en la sociedad mexica". In

Ragot, Natalie; Peperstraete, Sylvie e Olivier, Guilhem (orgs.), Hommage a Michel Graulich. Paris, École Pratique de Hautes Études, pp. 147-156.

Neurath, Johannes

2016 "Ritual und Inhomogene Raum-Zeit Konzeption in Mesoamerika". In KAMMLER, Henry (org.), Ethnologie des indigenen Mesoamerika: Ein Handbuch zur Einführung. Munich, Waxmann. 
FEDERICO NAVARRETE LINARES. ENTRE A COSMOPOLITICA E A COSMOHISTÓRIA: TEMPOS FABRICADOS...

Olivier, Guilhem

2015 Cacería, sacrificio y poder en Mesoamérica. Tras las huellas de Mixcóatl, "Serpiente de nube”. México, Fondo de Cultura Económica.

2010 "El simbolismo sacrificial de los mimixcoa: cacería, guerra, sacrificio e identidad entre los mexicas". In Luján, Leonardo López e Olivier, Guilhem (orgs.), El sacrificio bumano en la tradición religiosa mesoamericana. México, Instituto de Investigaciones Históricas, UNAm-Instituto Nacional de Antropología, pp. 453-482.

1995 "Les Paquets sacrés ou la memoire cachée des indiens du Mexique Central (xve-Xvie siècles)". Journal de la Société des Américanistes, 81: 105-141.

Romero García, Juan Manuel

1995 Conceptualización de la ofrenda, la penitencia y el sacrifico entre los nabuas prehispánicos. México, tese, unAm.

SAHAGÚN, Bernardino de

1950-70 The Florentine Codex, General History of the Things of New Spain. Charles Dibble e Arthur J.O. Anderson, trads. Santa Fe, The School of American Research-University of Utah.

SoustelLE, Jacques

1956 La vida cotidiana de los aztecas en vísperas de la conquista. México, Fondo de Cultura Económica.

STENGERS, Isabelle 2005 “The Cosmopolitical Proposal”. In Latour, Bruno e Weibel, Peter (orgs.), Making Things Public: Atmospheres of Democracy. Cambridge, The MIT Press, pp. 9941004.

Viveiros de Castro, Eduardo

2002a "O mármore e a murta: sobre a inconstância da alma selvagem". In $A$ inconstância da alma selvagem. São Paulo, Cosac \& Naify, pp. 181-264.

2002b "Perspectivismo e multinaturalismo na América indígena". In A inconstância da alma selvagem. São Paulo, Cosac \& Naify, pp. 345-400.

2008 "Xamanismo transversal: Lévi-Strauss e a cosmopolítica amazônica". In QueIroz, R. de C. e Nobre, R.F. (orgs.), Lévi-Strauss: leituras brasileiras. Belo Horizonte, Editora UFMG, pp. 79-124. 


\title{
Between Cosmopolitics and Cosmohistory: Fabricated Times and Shaman Gods among the Aztecs
}

\begin{abstract}
This article proposes a new interpretation of the mythology and religion of the Aztecs (or Mexicas), together with their politics. Although the Mexicas were a hierarchical society with a centralized power structure, they practiced a cosmopolitics that can be likened to that of the Amazonian peoples. In this sense, their stories about the creation of the world show how human and non-human beings with shamanic powers were transformed into gods, and how they in turn created mankind in a relation of constant transformation and exchange. Also analyzed are the ways in which Mexica cosmopolitics sought to maintain the workings of a stratified society together with the workings of a cosmos in which deities and humans were hierarchically related. Their aim was to construct verticality in a pluriverse which always tended to revert to horizontal transformations, and to manage the relations between different beings and realities through cosmohistory.
\end{abstract}

KEYWORDS: Cosmogony, Shamanism, Cosmopolitics, Hierarchy.

Recebido em março de 2016. Aceito em agosto de 2016. 